\title{
TECNOCIÊNCIA, CORPOS, GÊNERO E SEXUALIDADE
}

\author{
Daniela Tonelli Manica ${ }^{1}$ \\ Martha Ramírez-Gálvez ${ }^{2}$
}

O sexo-ciborgue restabelece, em alguma medida, a admirável complexidade replicativa das samambaias e dos invertebradosesses magníficos seres orgânicos que podem ser vistos como uma

profilaxia contra o beterossexismo.

(HARAWAY, 2000, p 40).

0 que dizem e fazem as tecnociências contemporâneas sobre corpos, gênero e sexualidade? Como pensar as relações entre concepções e práticas científicas sobre a diferença sexual, a sexualidade e a reprodução, considerando tanto o universo tecnocientífico (ciências biológicas, biomédicas), como nossas próprias reflexões, também (tecno)científicas, produzidas pelas ciências sociais e humanas em geral, sobre a mesma temática?

Nas humanidades, os estudos de gênero e os estudos sociais das ciências trazem, de matrizes disciplinares diversas (história, epistemologia e sociologia dentre as mais conhecidas, talvez), perspectivas críticas sobre a (tecno)ciência que procuram enfatizar seu caráter de empreendimento humano. Essas críticas buscaram, de alguma maneira, desestabilizar a ideia de que a ciência, de maneira neutra e objetiva, desvenda verdades universais; e ressaltaram os aspectos relacionados aos processos "sociais" e políticos que envolvem a produção do

\footnotetext{
${ }^{1}$ Professora Adjunta do Departamento de Antropologia Cultural, Universidade Federal do Rio de Janeiro, Brasil. danielamanica@ufrj.br

${ }^{2}$ Professora Adjunta do Departamento e do Programa de Pós-graduação em Ciências Sociais, Universidade Estadual de Londrina, Brasil. marthacerg@gmail.com
} 
conhecimento científico. Os estudos feministas sobre a ciência contribuem para essa perspectiva crítica, tendo como foco a análise de como as desigualdades de gênero, reproduzidas no interior das instituições científicas, perpassam a produção do conhecimento (SCHIEBINGER, 2008). As análises dos discursos científicos sobre diferença sexual, sexualidade, reprodução e raça ocuparam um lugar proeminente nessa perspectiva crítica, em consonância com as problematizações e a agenda política de diversos movimentos sociais (feministas e homossexuais, atualmente LGBT, queer, etnicorraciais, entre outros).

Nosso enfoque, neste dossiê, é tentar retomar um esforço de reflexão sobre os termos anunciados na chamada (tecnociência, corpos, gênero e sexualidade) focando especificamente no diálogo entre os estudos sociais da ciência (e, particularmente, com uma socioantropologia da ciência e da tecnologia) e os estudos de gênero. Propomos pensá-los em relação às análises que ambos campos fazem acerca da produção de conhecimento e intervenções tecnocientíficas sobre os corpos sexuados/generificados. ${ }^{3}$

A temática de "gênero" se constitui inicialmente a partir de uma crítica à ideia da naturalização e determinismo da diferença sexual, dada como certa e definitiva, como defendem alguns enfoques nas ciências biológicas e biomédicas. 0 conceito de gênero, na sua dimensão teórica e política reflete, da perspectiva das ciências sociais e humanas, o esforço de estudar, pensar e desenvolver a proposta de que as assimetrias, hierarquias, desigualdades observadas entre homens e mulheres estão relacionadas a aspectos sociais, históricos, políticos e não às diferenças ancoradas em seus corpos, ou em seus caráteres sexuais ou reprodutivos. Além do mais, busca analisar como as características sexuais são compreendidas e representadas.

Concomitantemente ao binarismo sexual surge a temática da sexualidade, em princípio pensada como um fato biológico que visa a reprodução. No entanto, os estudos sobre sexualidades, que tiveram nas últimas décadas um expressivo aporte de pesquisas e reflexões, desenvolvem a crítica ao pressuposto decorrente da diferença sexual: de que a sexualidade estaria atrelada aos propósitos reprodutivos dos corpos e que, portanto, a heterossexualidade, por ser a relação

\footnotetext{
${ }^{3}$ A ideia da organização deste dossiê, e de abrir sua chamada pública, veio do diálogo produzido pela mesa "Estudos antropológicos sobre medicina e tecnociência: históricos, temáticas e desafios", na IV Reunião de Antropologia da Ciência e da Tecnologia - ReACT, realizada em Campinas, 2013. Video disponível em: http://www.ige.unicamp.br/react/content/mídia
} 
que produz embriões, fetos, famílias, seria a forma natural ou óbvia de expressão da sexualidade.

A proposta do dossiê advém da percepção de que, ainda longe de ultrapassados os embates entre "sexo" e "gênero", expressos na diversidade e complexidade dos movimentos sociais contemporâneos (inclusive os ligados a gênero e sexualidade), o "corpo" (re)adquire uma certa centralidade. Neste sentido, propusemos reativar essas articulações, recuperando, nesse movimento, uma autora fundamental para pensá-las: Donna Haraway. Sua escrita criativa e politicamente sensível, e por vezes incômoda ou até polêmica, expressa ao mesmo tempo a potência e a complexidade desse lugar: o de tentar construir conhecimento científico sobre o conhecimento científico. Haraway vem tentando positivar a existência desse nosso lugar de fala (cada vez mais formatado, controlado, acelerado e restrito) para pensá-lo de uma perspectiva crítica, que leve em conta todas as especificidades possíveis, disciplinares, locais, e comportando todas as intersecções que incidem sobre o mundo vivido, inclusive em sua atualização a partir da tecnociência.

\section{SEXO, GÊNERO E CIÊNCIA}

0 conceito de gênero, central para as construções e classificações de sistemas sociais de diferença, aglutina, portanto, várias ideias que confluem na dessubstancialização da diferença sexual, pensada para além das características sexuadas dos corpos. Também não é um conceito que se utilize, em alguns casos, sem tensões no campo analítico e político, questão que precisaria de um amplo mapeamento e análise. Mas, o que se pode observar é que o conceito de gênero sofre diferentes apropriações e entendimentos conforme os referenciais teóricos, históricos e políticos nos quais ele é enunciado ${ }^{4}$.

Ao refletir sobre gênero na história das ciências, Maria Margaret Lopes (2006) observa que sua incorporação como perspectiva de abordagem teórica e possível linha de análise é recente; embora, como lembra Maria Teresa Citeli, não o fosse na antropologia, na qual se procurava evitar "explicações deterministas ou relativistas, refutando categorias universalizantes de análise e procurando dissolver identidades fixas" (CITELI, 2000, p. 65).

Ao observarmos os estudos sobre gênero e ciência, ou em alguns casos sobre mulher e ciência no Brasil, notamos que parte dos esforços tem sido focada,

\footnotetext{
${ }^{4}$ Para uma ampla revisão sobre este assunto, ver Haraway (2004), dentre outras autoras.
} 
principalmente, sobre a ausência ou a invisibilidade de mulheres no mundo da ciência. Diversos trabalhos objetivam resgatar histórias ignoradas de mulheres em vários campos do conhecimento, além de refletir sobre os contextos que possibilitaram ou não a inserção das mesmas em algumas áreas específicas.

Os estudos sobre gênero e ciência têm uma tradição vinculada, na sua origem, a indagações feministas. Autoras como Evelyn Fox Keller, Sandra Harding, Helen Longino, Londa Schiebinger, Anne Fausto-Sterling e Donna Haraway, entre outras, tornaram-se de grande referência nos estudos das ou sobre as ciências a partir das últimas décadas do século XX. Assumindo uma posição feminista e, em consequência fazendo uma crítica social, voltada especificamente para a análise da produção do conhecimento científico, estas autoras desafiaram os valores de universalidade, objetividade e neutralidade, introduzindo perspectivas que destacam a parcialidade e a situacionalidade da produção do conhecimento científico.

Estes estudos contribuíram também para problematizar determinados pressupostos conceituais, como, por exemplo, a oposição dicotômica entre natureza e cultura (que fundamenta a divisão de grandes áreas científicas, como ciências naturais x ciências sociais) e 0 binarismo sexual (homem/machos $\mathrm{x}$ mulheres/fêmeas como realidades dadas e fixas). Tais estudos são agrupados, fundamentalmente, em três linhas de pesquisa: "(1) a participação das mulheres na ciência; (2) 0 gênero nas culturas da ciência; (3) o gênero nos resultados da ciência" (SCHIEBINGER, 2008, p. 272, ênfase original).

Evelyn Fox Keller (2006) avalia que o projeto feminista das décadas de 1970 e 1980, que assumiu objetivos diversos conforme as linhas de pesquisa anteriormente citadas, tentava transformar a ciência, tornando-a mais humana e abrangente, conseguindo mudar a posição das mulheres na ciência e colocar a descoberto metáforas sexistas que povoaram o entendimento científico do mundo.

Um exemplo contundente desse olhar científico "enviesado" foi a crítica feita por Emily Martin (1991) à atribuição de certos traços presentes nos discursos científicos sobre os gametas sexuais humanos, que reproduziam expectativas sociais sobre mulheres e homens, ou o feminino e o masculino. Explorando uma série de descrições e narrativas em textos científicos estadunidenses sobre o óvulo e 0 esperma, ${ }^{5}$ Martin mostra como as concepções sobre o primeiro partem de ideias de uma célula-"noiva" ou "princesa", aguardando o resgate ou a salvação

\footnotetext{
5 Principalmente, neste caso específico, a autora se baseou em livros-texto para cursos de graduação em biologia e medicina da Universidade John Hopkins.
} 
pela célula-"noivo" ou "príncipe" (o espermatozoide fecundador), para versões variantes como a de uma femme fatale que ataca agressivamente sua vítima. Em ambos os casos, o objetivo principal seria a produção de uma célula-"bebê" (MARTIN, 1991, p. 500).

Em tal análise, Martin critica a relação entre as metáforas através das quais essas células são descritas, problematizando sua personificação/ antropomorfização e os pressupostos e expectativas que dizem respeito às projeções sobre o imaginário das relações de gênero em questão - isto é, as relações, inclusive de poder, que se estabelecem entre homens e mulheres em um determinado contexto social.

Segundo Keller (2006, p. 31-32), as mudanças ocorridas no universo científico não decorreram unicamente de uma ampliação da presença de mulheres nos campos das ciências, embora isto tenha ajudado "a restaurar a equidade no domínio simbólico em que o gênero operou por tanto tempo", mas principalmente do impacto que foi a transformação do significado de "gênero" desencadeada pelo feminismo de segunda onda.

Maria Teresa Citeli (2000), numa sistematização e análise sobre a produção em língua inglesa nesse campo, destaca como a crítica feminista teve grande influência advinda não só dos estudos de gênero, como também dos estudos sociais das ciências. A autora traça paralelos e homologias entre os estudos feministas sobre ciências e os estudos sociais da ciência, durante a década de 1980. Interessa destacar, para ampliar a tese de Keller, a contribuição de crítica radical que os estudos sociais da ciência introduziram acerca da produção do conhecimento, como sendo algo também perpassado por contingências sociais e políticas. Embora tal questão encontre alguma conexão com as formulações feministas sobre problemas teóricos, epistemológicos e políticos emergentes ao pensar mulheres, gênero e ciência, Citeli destaca que essas áreas tiveram desenvolvimentos paralelos, sem uma confluência explícita. Há, contudo, convergências e conexões que podem ser traçadas, e em parte a proposta desse dossiê, e dessa apresentação, é explorar essa possibilidade.

\section{CONFLUÊNCIAS ENTRE OS ESTUDOS DE GÊNERO E ESTUDOS SOCIAIS DA CIÊNCIA}

Citeli menciona que, apesar da diversidade de estudos feministas sobre ciência, é possível caracterizar duas grandes linhas: mulber e ciência e gênero $e$ 
ciência. Os primeiros dedicaram esforços para analisar a invisibilidade da participação das mulheres na ciência, que

resultaram em produtiva discussão sobre temas candentes para 0 feminismo e para os estudos sociais das ciências, como igualdade e diferença, natureza e cultura, aliando a história das mulheres nas ciências a discussões sobre gênero, epistemologia, metodologia científica e a autoridade [poder] conferida por nossa sociedade aos cientistas para falar em nome da natureza. (CITELI, 2000, p. 57).

Ao descrever a outra grande linha, gênero e ciência, a autora salienta os trabalhos de pesquisadoras que tentaram aproximar ou realizar um encontro produtivo entre os estudos de gênero e os estudos sociais da ciência. Cita, especialmente, um trabalho de Keller $^{6}$, no qual essa autora recorre a esses dois campos para, dentre outras questões, dissolver identidades fixas e dicotômicas de gênero e recusar a possibilidade de existência de uma "ciência feminista", dado 0 caráter social e histórico da própria ciência.

Apoiada na análise da trajetória da geneticista Bárbara McClintock, que ganhou 0 prêmio Nobel pelas pesquisas que fez sobre diferenças genéticas internas ao milho, Keller argumenta que, se tivesse que falar sobre suas pesquisas, McClintock defenderia que gênero, de certa maneira "se desvanece quando se trata de fazer ciência" (CITELI, 2000, p. 69).

Para participar da comunidade científica, portanto, importaria menos qualquer condição feminista ou ligada ao feminino (novos valores, metas ou 0 reconhecimento de uma certa especificidade), do que seguir a lógica interna do diálogo disciplinar e da produção do conhecimento científico. Na tentativa de dosar determinismos e relativismos decorrentes do uso de dicotomias de sexo/gênero e natureza/cultura, Keller desloca o foco de análise do "sexo" para 0 "gênero" e do "gênero" para a "construção da ciência". Há, neste posicionamento (politicamente complexo da perspectiva feminista), uma preocupação das cientistas em preservar um sentido para o termo "ciência". Segundo Citeli,

A celebração da diferença no interior da ciência (não de ciência diferente) parece constituir um claro avanço tanto sobre a visão monolítica da ciência que ameaça excluir diversidade, como sobre a

\footnotetext{
${ }^{6}$ KELLER, E. Fox. The gender/science system: or, is sex to gender as nature is to Science? Vol. 2, No. 3, Feminism \& Science, 1 (Autumn, 1987), pp. 37- 49, apud Citeli (2000).
} 
visão relativista que ameaça negar significado especial para a categoria ciência. Seria por isso que os defensores da idéia da diferença na ciência se opõem às tendências relativistas pós-modernas: eles têm em mente os constrangimentos impostos pela recalcitrância da natureza, para lembrar que a natureza não pode ser espelhada, mas de fato existe. A única verdade que sabemos é que a natureza (tal como 0 sexo) não pode ser apagada da existência; ela persiste, além da teoria, como lembrança de nossa humilde condição de mortais (CITELI, 2000, p.71).

Desta forma, ao ter que lidar analítica e politicamente com a questão de "como" e "o que" entender a partir de corpos, gênero e sexualidade, e sua recalcitrância, os estudos feministas da ciência compartilharam, e muitas das vezes anteciparam, como mapeia Citeli (2000), a dificuldade de se recorrer a conceitos analíticos como "natureza" ou "sociedade". Ao mesmo tempo, perceberam a importância de se levar em conta os efeitos do conhecimento e da produção tecnocientífica sobre o mundo - e, sobretudo, sobre os corpos, no caso, generificados e/ou reprodutivos.

0 reconhecimento de um domínio que "ultrapassa" as contingências sociopolíticas da construção do conhecimento científico (as relações de poder que envolvem gênero, bem como outros marcadores de diferença como raça, classe); assim como a tentativa de reter algo que é recalcitrante, que em certa medida independe desses outros agenciamentos (ainda que não negue a sua existência e seus efeitos perversos), podem, talvez, ser pontos de convergência entre os estudos sociais das ciências e os estudos de gênero. Para ambos, a "materialidade" do mundo, das coisas, dos corpos se coloca como uma indagação sobre a qual se constitui a reflexão e a crítica.

0 conceito de gênero, formulado para destacar as relações e concepções sociais (frequentemente de poder) que se estabelecem a partir da percepção de uma diferença ancorada nos corpos (a diferença "sexual" e seus desdobramentos para sexualidade e reprodução), traz à tona a discussão sobre a "materialidade" dos corpos, que aparece nos estudos de gênero e ciência, também através da problematização e da crítica aos pressupostos que fundamentam a construção do conhecimento científico sobre a diferença sexual. ${ }^{7}$ A concepção do "corpo" como base material, fixa e imutável, subsidia várias formulações dos estudos de gênero e, ao mesmo tempo, serve de fundamento para várias formas de conhecimento científico (a biologia e a medicina, por exemplo).

${ }^{7}$ Ver, por exemplo, Fausto-Sterling (2000) e, no caso brasileiro, Rohden (1998, 2001). 
Todavia, tais ideias servem como a base a partir da qual (e até "contra" a qual) se constituíram algumas críticas feministas. Elisabeth Grosz (2000), faz uma análise crítica sobre a compreensão que diversas correntes do feminismo tiveram do corpo como entidade biológica, imutável, reproduzindo a oposição cartesiana de corpo x mente. Esta autora, ao procurar outras inspirações filosóficas para superar concepções dicotômicas e mecanicistas, observa em Espinosa a possibilidade do deslocamento do dualismo cartesiano e a superação de visões e metáforas mecânicas que impregnaram visões sobre o corpo, tanto no mundo científico, quanto em algumas críticas feministas.

Não há atributos essenciais, não há natureza "inerente" ao organismo. Deslocando o dualismo mente/corpo, Espinosa atinge também a oposição dominante entre natureza e cultura, entre essência e construção social. Em suma, corpos, individualidades, são tecidos históricos, sociais, culturais, da biologia. (GROSZ, 2000, p. 65).

Tal visão antiessencialista, que compreende o corpo enquanto concretude também histórica e não apenas como uma concretude biológica, não como um estado fixo, mas como um processo de vir-a-ser, vai ter grandes repercussões no pensamento pós-estruturalista, que visa superar os diversos dualismos, decorrentes da visão cartesiana.

Assim, parte dos embates (internos, e contemporâneos) dos estudos sociais das ciências e dos estudos de gênero e ciência envolvera uma crítica à ênfase reativa na cultura, isto é, aquela que enfatizava 0 caráter social/cultural/político ("construído") do conhecimento científico e que minimizava a "recalcitrância" do mundo, do corpos e a abrangência e eficácia de certos processos e procedimentos científicos.

Esse processo leva, para a própria análise da perspectiva socioantropológica, ao que Haraway caracteriza como uma espécie de "terapia de eletrochoque epistemológico" (HARAWAY, 1995, p. 13), que coincide em determinados aspectos com o que outros autores vão caracterizar como a "virada ontológica". 8

Trata-se de uma mudança do foco de uma abordagem socioantropológica sobre a dimensão representacional (simbólica, linguística) da ciência, com a sua "epistemologia" (que inclui os pressupostos epistemológicos e conceituais

\footnotetext{
${ }^{8}$ Sobre os impactos dessa perspectiva nos estudos de ciência ver, por exemplo: Latour, 1995 e 2005; Mol, 1998, 2002, 2014; Woolgar \& Lezaun, 2013, dentre outros.
} 
"modernos" e "ocidentais" de natureza e cultura, por exemplo) para uma apreensão da ciência "em ação" (LATOUR, 1997), levando em conta todos os agenciamentos "não-humanos" que a compõem, ou ainda, em direção às "múltiplas ontologias" nela implicadas (MOL, 2002). Essa perspectiva procura romper com 0 pressuposto da validade analítica a priori daqueles conceitos e oposições, e abrir o enfoque e a crítica socioantropológica para além do que se entendia como seus aspectos "humanos" (sociais/culturais/políticos).

Este mesmo movimento faz a antropóloga Marilyn Strathern, ao colocar o material etnográfico melanesiano em diálogo com as pautas feministas e marxista (2006). Arriscando se contrapor aos pressupostos políticos e identitários que fundamentavam ambas perspectivas (a subordinação universal das mulheres e a diferença sexual como algo ancorado nos corpos sexuados, no primeiro caso; e a relação de propriedade privada e a alienação do trabalho como também universais, no segundo), a autora defende que a perspectiva antropológica perde muito ao partir de "natureza" e "cultura" como conceitos analíticos. Inclusive, levando em conta as teorias sobre pessoa, gênero e socialidade no contexto etnográfico por ela pesquisado, essa distinção não faria nenhum sentido (STRATHERN, 1980, 2006).

Ao falar sobre a oposição entre natureza e cultura, Haraway (1999a, p. 156), por sua vez, inspirada em Bruno Latour', defende que as realidades não podem ser capturadas e analisadas nessa polaridade, mas no cruzamento, na substituição e nas traduções mediante as quais os actantes [agentes] modificam sua competência. A autora manifesta que, junto ao projeto de Latour (1995), suas análises sobre a ciência são amodernas, indicando dessa forma, que não se trata de pensar o progresso racional da ciência, nem de desvendar pacientemente uma natureza subjacente, ou ainda de demonstrar a "construção social da ciência e da natureza" que localize o agenciamento em apenas humanos. No lugar disso, ao acionar o termo amoderno, a autora se refere a uma visão da história da ciência como cultura,

que insiste en la ausencia de principios, iluminaciones y finales: el mundo siempre ha estado en el medio de las cosas, en una conversación práctica y no regulada, llena de acción y estructurada por un conjunto asombroso de actantes y de colectivos desiguales conectados entre si. (...) La forma de mi historia amoderna tendrá una

\footnotetext{
${ }^{9}$ LATOUR, Bruno. Postmoderns? No, simply Amodern! Steps toward an Anthropology of Sciences. Studies in the History of Philosophy and Science, 21(1), 1990, p. 145-71, apud Haraway (1999a).
} 
geometría diferente, no será la del progreso, sino la de la interacción permanente y multiforme mediante la que se construyen las vidas y los mundos, los humanos y los no humanos. (HARAWAY, 1999a, p. 131).

Concordando com o sentido atribuído por Latour ao projeto da modernidade, ${ }^{10}$ e com a defesa de que esta nunca existiu de fato ("jamais fomos modernos"), Haraway retoma a formulação latouriana de que a prática científica tem sido amoderna, argumentando inclusive pelo desaparecimento da linha divisória entre 0 "realmente científico" ( 0 ocidental) e a "etnociência e outras expressões culturais" (todos os demais). Desse modo, estes dois autores localizam o estudo das práticas científicas na agenda dos estudos culturais e políticos; com a consequente revisão do que se entende por cultura, sociedade e política. Essa crítica resvala na operacionalidade conceitual da ideia de "construção social":

En concreto, no podemos hacer una crítica de la ciencia y de sus construcciones de la naturaleza partiendo de una creencia vigente en la cultura o la sociedad. En la forma del construccionismo social, esa creencia ha fundamentado la estrategia principal de los radicales de la ciencia de izquierda, feminista y antirracista. Continuar con esa estrategia, sin embargo, es seguir deslumbrados por la ideología de la ilustración. No bastará para abordar la ciencia como construcción social o cultural, como si la cultura o la sociedad fueran categorías trascendentes, más de lo que lo son la naturaleza o el objeto. Fuera de las premisas de la ilustración - es decir, de lo moderno - los pares binarios de cultura y naturaleza, ciencia y sociedad, lo técnico y lo social, pierden su cualidad co-constitutiva y opositiva (HARAWAY, 1999, p.156).

Seguindo essas perspectivas, e no que diz respeito a gênero e ciência, 0 trabalho de Nelly Oudshoorn (1994) é outra referência importante para mostrar que as tecnologias biomédicas têm um papel crucial para dar forma ao "corpo". Ao falar de tecnologias biomédicas, essa autora se ocupa dos aspectos materiais das ciências biomédicas, abandonando uma perspectiva de análise crítica que pensava a ciência apenas em termos de textos e ideias, uma vez que a mesma tem "efeitos materiais que proporcionam aos cientistas os instrumentos para atribuir sexo ao mundo em que vivemos, através da criação de produtos materiais" (CITELI, 2000. p. 75).

\footnotetext{
${ }^{10}$ Modernidade, grosso modo, entendida como a separação radical/absoluta entre a representação das coisas (ciência/tecnologia) e a representação dos humanos (política e justiça).
} 
Assim, ao mostrar a coincidência entre a ampliação do conhecimento científico sobre os processos hormonais sexuais e reprodutivos, e sobre a possibilidade de manipulação e produção farmacêutica de hormônios sintéticos com finalidades endocrinológicas diversas (como a contraceptiva, por exemplo), o trabalho de Oudshoorn (1994) contribui para questionar aspectos até então pensados como exclusivamente "naturais". Um dos argumentos mobilizado neste livro, cuja tradução para o português poderia ser algo como "Para além do corpo natural", é que a ideia de que os ciclos reprodutivos femininos "naturalmente" duram 28 dias foi reforçada, amplificada e reificada pela formatação convencional da pílula anticoncepcional, que causa efetivamente a existência de ciclos "menstruais" (ainda que não férteis) com essa periodicidade (OUDSHOORN, 1994. p. 136).

Da mesma forma, as contribuições trazidas por Donna Haraway estão amplamente ancoradas na dimensão material do mundo, dos corpos e da própria tecnociência. A figura do ciborgue como um mito irônico para o feminismo (HARAWAY, 2000), assim como a dos primatas não-humanos (1989), ou do Oncomouse $^{\mathrm{TM}}$ (1997), são, como coloca a autora, figurações que enfatizam a importância desse domínio material-semiótico que interessa pensar.

Como vimos, a crítica aos dualismos, e às oposições dicotômicas que informam nosso entendimento do mundo (e através do qual contrastamos natureza e cultura, masculino e feminino, por exemplo), tornou-se uma questão essencial para os estudos de gênero e para compreender a complexidade de fenômenos envolvidos entre a tecnociência e suas relações com corpos, gênero e sexualidades. Como menciona Groz (2000), além do pensamento dicotômico classificar e hierarquizar, um termo não admite a independência do outro, considerando sempre, apenas, seu antagonismo. Assim, para a autora, a explicação ou definição da "existência" estaria limitada ao emprego de um termo, ou de seu oposto (por exemplo, mente ou corpo; macho ou fêmea; masculino ou feminino; natureza ou cultura), o que provoca a impossibilidade de intermediações da diferença (de três ou quatro elementos, de uma diversidade).

As diversas críticas ao pensamento dicotômico, que envolvem uma produção densa e muito variada em diferentes campos do conhecimento, surgem como enunciação de pensamentos não mecânicos, não dualistas e antiessencialistas, que redundaram na formulação de outros entendimentos sobre 0 próprio conceito de gênero, para além do binarismo sexual e do sistema sexo/gênero, este último chave para a discussão não só de formulações teóricas de 
gênero, mas também para pensar especificamente sua articulação com a tecnociência.

\section{DO SISTEMA SEXO/GÊNERO À PLASTICIDADE TECNOLÓGICA DO GÊNERO}

Margaret Lopes (2006, p. 46), atribui a formulação pioneira da distinção sexo/gênero à socióloga feminista Ann 0akley ${ }^{11}$, na qual esta autora distingue os atributos biológicos, inatos da diferença sexual ("sexo") dos atributos de gênero socialmente adquiridos pela socialização ("gênero").

A antropóloga Gayle Rubin (1975), por sua vez, contribui para os estudos de gênero na década de 1970, ao analisar a dimensão política contida no sistema sexo/gênero como o processo que transformava a sexualidade biológica (fêmeas) em produtos da atividade social, no sistema de parentesco e da troca de mulheres, formulado por Claude Lévi-Strauss; na enunciação do complexo de Édipo, como constituição do desejo, de Sigmund Freud; e na divisão sexual do trabalho, de Karl Marx.

Rubin via em tais formulações uma dimensão política: a origem da opressão das mulheres numa "heterossexualidade compulsória". Embora tal autora não tenha dimensionado as implicações de sua análise na sexologia, na medicina ou na biologia, ela se tornou um ponto de inflexão para trabalhos posteriores, tais como os de Judith Butler que, não obstante, criticaram a permanência da dicotomia natureza/cultura nos postulados de Rubin.

Butler (2003) discutiu os processos de inteligibilidade da sexualidade heteronormativa e reprodutiva, mediante os quais assumimos identidades e subjetividades sexuadas, generificadas e racializadas, pré-formatadas no interior de estruturas de poder e reproduzidas como atos de performatividade. 0 sujeito é pensado por esta autora não como uma realidade pré-discursiva, mas como uma "uma estrutura linguística em formação", como um processo de devir sem fim, no qual é possível "reassumir ou repetir a sujeitidade de diferentes maneiras" (SALIH, 2012, p. 11).

Ao descolar sexo, performance de gênero e sexualidade (desejo), a autora coloca em evidência a instabilidade que perpassa as "identidades de gênero", conceitualizando o mesmo como "una forma de hacer, una actividad incesante

\footnotetext{
${ }^{11}$ OAKLEY, Ann. Sex, Gender and Society. London: Maurice Temple Smith, 1972, apud Lopes (2006, p. 48).
} 
performada, en parte, sin saberlo y sin la propia voluntad (...) una práctica de improvisación en un escenario constrictivo." (BUTLER, 2006, p.13).

Todavia, como lembram Preciado (2007) e Haraway (2004), entre outras, 0 sistema sexo/gênero e seu correlato "identidade de gênero" foram termos enunciados na década de 1950, no contexto de laboratórios de pesquisa e de intervenção "terapêutica" sobre as diferenças sexuais, liderados nos Estados Unidos por John Money e Robert Stoller. A ideia de uma "identidade de gênero" decorre de um embate entre o determinismo biológico (morfologia, hormônios, genes, etc.) e o construcionismo social (aspectos culturais e psicossociais), produzida por uma miríade de discussões no campo da psicanálise, da sexologia, da endocrinologia, da psicologia comparada, sob forte influência do feminismo de segunda onda, mais especificamente, como afirma Haraway (2004), de uma versão funcionalista e essencializante da máxima de Beauvoir "não se nasce mulher". Interessa sublinhar, como o faz Haraway que:

A história das reformulações políticas de gênero pelas feministas ocidentais depois dos anos sessenta deve passar pela construção de sentidos e tecnologias de sexo e gênero nas ciências da vida normalizadoras, liberais, terapêutico-intervencionistas, empiricistas e funcionalistas (HARAWAY, 2004, p. 215).

Beatriz/Paul B. Preciado (2007), destaca que John Money substituirá a ideia do século XIX de sexo como uma característica fixa pela da "plasticidade tecnológica do género", ao se referir ao uso de hormônios e técnicas cirúrgicas para tratar crianças intersex ou, como afirma Corrêa, para "corrigir uma ambiguidade, seja ela percebida como um defeito de nascimento, definido por outros, seja ela [cirurgia] feita para corrigir um defeito autodefinido" (CORRÊA, 2004, p. 176).

Preciado observa no conceito de gênero introduzido por Money o

instrumento de una racionalización de la vida en la que el cuerpo no es más que un parámetro. El género es ante todo um concepto necessário para la aparición y el desarrollo de un conjunto de técnicas de normalización/transformación de la vida: la fotografia de los "desviados sexuales", la identificación celular, el análisis y el tratamiento hormonales, la lectura cromosómica, la cirugía transexual e intersexual...(PRECIADO, 2007, s/p) 
Nesse contexto, há o surgimento de um regime específico da sexualidade, que Preciado intitula de "posmoneysta", para o qual a noção de gênero é considerada levando em conta sua plasticidade, atrelada ao desenvolvimento de diversas biotecnologias. A normalização dos corpos não é apenas representacional e performativa, mas materialmente incorporada na biologia dos corpos. Desse modo, o corpo não pode ser mais visto como matéria passiva, mas com uma entidade tecno-orgânica, cuja normalização depende de hormônios, silicone, técnicas cirúrgicas.

Preciado chama a atenção acerca da ausência dessa biotecnologia produtora de gênero na formulação teórica de Judith Butler, ao esta enunciar o gênero fundamentalmente como performatividade e discursividade. Considera, ainda, que uma análise performativa da identidade limita a mesma a um efeito que ignora as diversas tecnologias de incorporação que funcionam nas diferentes inscrições da identidade. Para Preciado, isso implica ignorar os processos políticos que fazem com que algumas performances sejam consideradas naturais e outras não: "no se trata simplemente de señalar el carácter construído del género, sino ante todo de reclamar la posibilidad de intervenir en esa construcción al punto de crear las formas de representación somáticas que pasarán por naturales" (PRECIADO, 2007, s/p).

Deste modo, na proposta analítica de Preciado as biotecnologias ganham um lugar de destaque, ao serem essenciais e definidoras das performances que seriam mais ou menos naturais. Tal formulação nos permite pensar em "políticas de sexuação" que fariam parte das "tecnopolíticas de gênero", através das quais se determinam os agentes e normas regulatórias que definem quais sujeitos têm acesso a certos procedimentos cirúrgicos ou químicos capazes não somente de regular a fecundidade, mas também de embaralhar, acentuar ou diminuir caracteres sexuais secundários, ou "adequar" genitálias aos traços definidores de machos e fêmeas. Todavia, a própria potência inerente aos recursos e substâncias existentes, e relativamente "disponíveis", para uma modificação hormonal ou cirúrgica do corpo, cria, em contraste e paralelamente, a possibilidade de usos não tutelados de tais recursos, abrindo alguma margem para a auto-determinação de pessoas trans, questionando, como afirma Cabral (2005, p. 76),

la diferencia sexual misma como relato fundante de un mundo presumiblemente habitado sólo por hombres y mujeres "naturales e originales", relato naturalizado que $\tan$ a menudo, y $\tan$ sangrientamente, excluye del texto y de la vida a tod*s $1 *$ s demas" 
0 desenvolvimento dessas biotecnologias que permitem a "sexuação" dos corpos - seja conforme protocolos terapêuticos ou seja nos usos não tutelados pelas instancias legitimadas de intervenção e produção de conhecimento tornou-se essencial para operar os "trânsitos" e modificações de sexo em seus aspectos corporais/encarnados/materiais. A atual visibilidade política de pessoas trans poderia ser também considerada possível graças à circulação de hormônios, silicone e à luta pelo acesso a cirurgias de mudança de sexo, processos para os quais as tecnociências contribuíram de maneira significativa, e em moldes frequentemente afinados às normatividades vigentes (sobre gênero e sexualidade, principalmente).

Esse processo remete também à vigência de uma biopolítica, da "vida" como objeto sobre o qual operam diretamente as formas de governamentalidade, que se torna alvo da organização, regulação e controle através do dispositivo da sexualidade (FOUCAULT, 1988 e 2005). Ao atualizar as ideias de Michel Foucault, Paul Rabinow e Nikolas Rose propõem usar o termo biopolítica para se referir a "todas as estratégias específicas e contestações sobre as problematizações da vitalidade humana coletiva, morbidade e mortalidade, sobre as formas de conhecimento, regimes de autoridade e práticas de intervenção que são desejáveis, legítimas e eficazes" (RABINOW \& ROSE, 2006, p. 28).

Nesse contexto, novas disputas políticas emergem sobre 0 direito à vida, ao corpo, à saúde. Mantendo-se fiel à perspectiva foucaultiana de poder, estes autores observam que o biopoder não deve ser considerado como o suporte de um conjunto único de interesses dominantes, mas é extensivo a uma "rede fina de convenções tradicionais, obrigações recíprocas", dentro de uma economia moral que envolve todos os agentes que têm alguma autoridade sobre a vida humana, inclusive movimentos sociais reformadores (RABINOW \& ROSE, 2006, p.36, 37). Ao introduzirem planos de análises micro e macro ou molar e molecular, nos termos deleuzianos, os autores apresentam um campo heterogêneo de disputas políticas e de atores, com objetivos, táticas e estratégias diversas que, além do Estado, envolve os sujeitos que atuam sobre si mesmos, seja sujeitados/alinhados aos discursos de verdade, seja através de dissidências ou de novos modos de individuação/subjetivação atrelados ao corpo e à vida.

\section{A COMPOSIÇÃO DO DOSSIÊ}

Os aspectos antes elencados servem de pano de fundo para as diversas temáticas/pesquisas e enfoques analíticos dos textos selecionados neste dossiê. 
Observamos os desdobramentos desses processos críticos, e o acionamento, por exemplo, de concepções de gênero inspiradas, especialmente, em autoras como Marilyn Strathern, Judith Butler e Donna Haraway. Embora estas desenvolvam suas perspectivas sobre gênero em tradições disciplinares e em contextos de análise muito diversos, confluem, como vimos, na recusa da dicotomia natureza/cultura como um pressuposto analítico e, em consequência, posicionam-se contra a proposta de pensar gênero como meras atribuições sociais relativas a corpos sexuados, pensados como realidades dadas, fixas, prédiscursivas.

Estas autoras contribuem para um movimento inverso, de trazer 0 gênero para os corpos, o que implica subverter/romper a ordem tradicional descrita no sistema sexo/gênero, de que o corpo sexuado seria a matriz para a elaboração de concepções culturalmente variáveis sobre ele.

No caso de Butler (2003), gênero é pensado como resultado de uma política sexual heteronormativa e reprodutiva que é tanto organizadora como acionada por diversos aparatos/sistemas reguladores, tais como a medicina e 0 direito, cujos protocolos são maneiras de afetar, intervir, normatizar e normalizar a plasticidade sexual e corporal.

Os estudos mais contemporâneos que se apoiam na articulação entre "gênero" e "ciência" contribuem para reformular criticamente esses dois termos. No caso do "gênero", este pode passar a ser considerado uma complexa matriz que opera para pensar e performar, ou fazer agir, corpos, sexualidades e seus aspectos (anti, ou ainda, além) reprodutivos. No que diz respeito a "ciência", esta passa a ser pensada não apenas como um conhecimento eminentemente filosófico e reduzido aos universos restritos do mundo acadêmico/universitário, mas considerada, sobretudo, na sua dimensão técnico-material e na sua articulação com as políticas de inovação e desenvolvimento tecnológico. Ou seja, em sua dimensão tecnocientífica, considerando seu aspecto biopolítico.

$\mathrm{Na}$ área biomédica especialmente, mais presente no conjunto de artigos que selecionamos a partir da temática desse dossiê, e que tem certamente mais a ver com corpo, gênero e sexualidade, a tecnociência aparece objetivada pela produção de medicamentos, hormônios e técnicas cirúrgicas, por exemplo. Assim, opera simultaneamente a produção de corpos, pessoas e subjetividades: seja produzindo efetivamente novas vidas humanas, como é o caso da reprodução medicamente assistida, seja no que contribui para o ajustamento (ou para a subversão) dos modelos normativos de gênero e de sexualidade, como por exemplo com a utilização de hormônios para finalidades diversas. 
Partindo do pressuposto de que ciência e tecnologia se configuram como dispositivos de produção de verdades e de intervenções sobre o mundo, e sobre os corpos em particular, propusemos a realização deste dossiê, visando publicar trabalhos que analisassem as implicações do conhecimento científico e sua apropriação tecnológica na produção de convenções e intervenções sobre os corpos. 0 objetivo proposto foi que tais análises se debruçassem sobre as tensões e relações políticas destes processos, sobre o caráter sociopolítico da tecnociência na definição de legitimidades ou ideias regulatórias (normalidades e/ou naturalidades) que afetam a existência cotidiana das pessoas, validando (pre)conceitos e produzindo hegemonias e estigmas de certos traços vinculados aos corpos generificados. Buscamos, também, selecionar contribuições que analisassem agenciamentos mediante a apropriação de intervenções biotecnológicas na produção de transformações corporais, que trouxessem dissociações nas convencionais correspondências entre corpo, gênero e sexualidade.

Pesquisas que buscam pensar essas relações (entre tecnociência, corpos, gênero e sexualidades) inevitavelmente mobilizam a visibilidade e a compreensão de aspectos múltiplos que envolvem muito além daquilo que pode ser imaginado como algo restrito a um universo (ou campo) científico fechado. Nesse sentido, incluem agentes diversos como substâncias e seus princípios ativos, usuários/as dos sistemas de saúde, ativistas de diversas afinidades políticas, médicos e cientistas, pesquisas clínicas, populações-alvo de intervenções biomédicas, laboratórios científicos e farmacêuticos, os diversos tipos de mercados farmacêuticos, biomédicos e eróticos, como também os aparelhos de regulamentação médicos e jurídicos dos processos sociotécnicos.

Em outras palavras, os estudos sobre tecnociência, em diálogo com as temáticas de gênero e sexualidade, ao levar em conta seus múltiplos efeitos sobre corpos (não apenas humanos, considerando por exemplo pesquisas científicas feitas com animais), reverberam a importância de se ampliar a perspectiva socioantropológica sobre as ciências, produzindo um tipo de conhecimento crítico que não minimize a agência de todos os elementos heterogêneos que compõem os empreendimentos tecnocientíficos contemporâneos. Ou seja, uma crítica que seja capaz de absorver o impacto da virada ontológica e das rupturas epistemológicas colocadas pelo feminismo e pelo pós-estruturalismo, mas que consiga incorporálas ao mesmo tempo em que retém os temas e problemáticas constituídos (gênero, corpo e sexualidades) e constantemente realimentados pelas demandas dos movimentos sociais com os quais sempre estiveram em interlocução (feministas, LGBT, queer, etnicorraciais, e todas as suas dissidências e 
multiplicidades). Uma perspectiva socioantropológica que prescinda, portanto, de partir da oposição natureza x cultura como categorias analíticas para pensar gênero, mas que possa apreender criticamente a complexidade dos processos tecnocientíficos contemporâneos que envolvem corpos em suas dimensões "generificáveis", sexuais e reprodutivas. Corpos, nesse sentido, funcionam como uma ancoragem importante para pensar os processos nos quais se atualizam essas diversas linhas de força.

A concepção de tecnociência pressuposta em nossa chamada e no título deste dossiê se inspira diretamente na forma como Donna Haraway dela se apropria, e a redefine. Em uma tradução livre:

Tecnociência excede de maneira extravagante a distinção entre ciência e tecnologia, assim como aquelas entre natureza e sociedade, sujeitos e objetos, e o natural e artefatual que estruturaram o tempo imaginário chamado modernidade. (HARAWAY, 1997, p. 3)

0 ciborgue (HARAWAY, 2000) figura, para a autora, uma saída a noções e conceitos do Iluminismo, e problemáticas ao feminismo - como a ideia de natureza, de corpo e biologia, como entidades de uma ordem radicalmente diversa, e dicotomicamente oposta, à da ação humana (social, cultural, política, "artificial"). Suas obras reverberam um esforço mais amplo, presente também em diversos outros trabalhos, ${ }^{12}$ por encontrar soluções analíticas que dessem conta de tratá-los criticamente sem "jogar o bebê com a água do banho". Ou, em outras palavras, sem perder uma dimensão politicamente crítica, nem cair em armadilhas analíticas que envolvam uma outra forma de determinismo (o cultural), ou em um relativismo cultural radical.

Assim como o ciborgue incorpora uma possibilidade (ainda que híbrida) de escapar de uma distinção radical entre natureza e tecnologia, corpo e máquina - 0 que, por outra via, Latour faz ao propor a fusão naturezas-culturas (1995) também a proposta de uma abordagem feminista sobre a "tecnociência" se baseia numa tentativa de fusão (ciência + tecnologia), ou de ressaltar a importância da condição, e produção, sociotécnica nas ciências contemporâneas. Isso, ainda em um período no qual a palavra "inovação" não tinha adquirido a centralidade que ora possui, ao menos no contexto brasileiro. Para Haraway, "compreender tecnociência é um modo de compreender como naturezas e culturas se tornaram

${ }^{12}$ Já referenciados anteriormente. 
uma palavra só”, processo fundamental para entender como nós nos engajamos com o mundo atualmente (HARAWAY, 2015, p. 63).

Partindo dessa inspiração em Donna Haraway, abrimos 0 dossiê Tecnociência, corpos, gênero e sexualidade com a tradução de trechos da entrevista concedida por ela a Thyrza Nichols Goodeve em 1997 (HARAWAY, 1999b). "Quanto como uma folha", o título da entrevista transformada em livro (How like a leaf), se refere à passagem da entrevista na qual Haraway reconhece a arquitetura molecular que compartilhamos com os demais seres vivos, e que pode ser conhecida graças à possibilidade histórica (que envolve a própria tecnociência) de compreender esse "compartilhamento" em toda sua complexidade, interesse, prazer e intensidade (HARAWAY, no presente volume).

Essa passagem inspirou a seleção da imagem da capa deste número de Mediações, uma composição feita com folhas de samambaia, ${ }^{13}$ planta à qual Haraway também se refere logo no início do Manifesto Ciborgue, no trecho citado na epígrafe. A autora sugere que pensar o processo reprodutivo/replicativo das samambaias é uma boa estratégia para reconsiderar o pressuposto da diferença sexual binária, e da heterossexualidade, como dados universais sobre a reprodução biológica. Samambaias, assim como outras pteridófitas, possuem um processo complexo de reprodução, que envolve, de maneira grosseira e resumida: uma primeira fase, assexuada, na qual são produzidos esporos que, por sua vez, ao encontrarem o solo, germinam gametófitos "hermafroditas" (ou, em outras palavras, variações menores da planta, que possuem ao mesmo tempo os gametas femininos e masculinos). Esses gametófitos podem (ou não) se autofecundar, processo que gerará então a forma maior, e mais conhecida, da samambaia adulta (esporófitos), produtora por sua vez de novos esporos.

A complexidade e a multiplicidade reprodutiva das samambaias seria um exemplo, para Haraway, do quanto podemos pensar a partir das próprias narrativas científicas sobre a "natureza" - com todas as ressalvas a essa ficção/conceito - modelos alternativos ao binarismo sexual e, principalmente, aos determinismos que advêm dele. Outro exemplo nesse sentido, e também representado na bela montagem de Helen Apohrnsiri que ilustra a capa, é a reprodução nos cavalos marinhos, animais conhecidos pelo fato curioso de os machos da espécie serem aqueles que gestam e parem a prole.

\footnotetext{
${ }^{13}$ Imagem gentilmente cedida, para este fim, pela ilustradora Helen Ahpornsiri. Disponível em: helenahpornsiri.com Agradecemos a Pedro Ferreira pela indicação dessa imagem.
} 
Como enfatizamos anteriormente, os estudos de gênero, por terem corpo e corporalidades (em sua dimensão material e performática) como problemáticas fundantes e estruturadoras, contribuíram de maneira significativa para pensar determinadas questões também presentes nas discussões sobre as ciências. Como, por exemplo, o caso da radioatividade, em que se constrói e consolida a eficácia de determinadas substâncias e procedimentos tecnocientíficos, ao mesmo tempo em que se mobilizam questões de gênero, e da presença e atuação de mulheres no universo científico.

0 texto de Gabriel Pugliese, O gênero da ciência: reflexões sobre a Teoria Ator-Rede e a perspectiva feminista, propõe um interessante desafio: colocar em diálogo teorias feministas da ciência e a teoria Ator-Rede, a partir da discussão do "caso Marie Curie". Assumindo a perspectiva de gênero proposta por Marilyn Strathern, Pugliese analisa a "imagística sexual" nas diversas relações que compõem a trajetória do casal Curie, e que coincide com a história da descoberta da radioatividade, entre os séculos XIX e XX.

Trata-se de "fazer aparecer nas relações que circundam o 'Caso Marie Curie' os diversos modos em que o gênero se cristaliza em sua heterogeneidade, enfim, os 'mil pequenos sexos' que se multiplicam para territórios inesperados" (PUGLIESE, 2012, p. 25). É nesse sentido que o autor reflete sobre "como o gênero constitui a ciência, mas também como a ciência constitui o gênero" (2012, p. 26).

Pugliese desenvolve uma instigante proposta para os estudos de gênero sobre a tecnociência: fazer cruzar as certezas e incertezas das teorias ator-rede (ANT) com a perspectiva feminista ou da situacionalidade (standpoint theory). Assim, a partir do caso "caso Marie Curie" vemos como é possível, de uma perspectiva analítica, pensar e valorizar dois aspectos: por um lado, a dureza e extensão dos fatos científicos em questão (a invenção-descoberta da radioatividade) - isto é, sem negar sua "realidade" ou, talvez melhor dizendo, sua "estabilização", como propõe a ANT. E, ainda, por outro lado, gênero como um "operador de acessos e trunfos" para que esse processo acontecesse, perspectiva trazida pelos estudos feministas da ciência.

0 caso Curie permite problematizar também as incertezas presentes nessas duas abordagens teóricas: a possível obliteração da importância dos aspectos políticos que envolvem a situacionalidade dos sujeitos pesquisadores (como as dimensões de gênero, na sua acepção mais clássica: a presença/ausência e/ou os lugares hierarquicamente estabelecidos para mulheres nas ciências), crítica que por vezes é direcionada à ANT. No caso da perspectiva feminista, questiona-se a 
possibilidade de negação da neutralidade e objetividade de determinados fatos científicos, e sua independência em relação ao que diz respeito a aspectos como 0 próprio gênero dos pesquisadores. Como desenvolve Pugliese no artigo para este dossiê (2015, p. 84):

0 fenômeno da natureza, a radioatividade, operava como um centro de ressonância que obliterava as relações de poder. A cada nova estabilização da radioatividade, já carregada pelo devir-mulher em que se constituiu, eram criadas fissuras nas relações convencionais de gênero, na medida em que Marie Curie era arrastada junto com 0 fenômeno da natureza.

Ao entrecruzar os ganhos e perdas de cada uma dessas teorias, o autor caracteriza o caso Curie como uma "radiopolítica", na qual os aspectos acima elencados podem ser contrastados, verificando-se como operaram simultaneamente 0 "devir-mulher da radioatividade" e 0 "devir-radioatividade de Marie Curie". Pugliese constitui, assim, uma perspectiva analítica sobre este caso que incorpora as dinâmicas que envolvem ao mesmo tempo gênero e ciência, uma saída interessante para o debate aqui enfocado.

Outra maneira de trazer as articulações em questão é pensar como as temáticas de gênero e sexualidade são abordadas pela tecnociência contemporânea. Para a vida dos sujeitos, a tecnociência aparece como uma instância regulada ou ajustada aos modelos de justiça e verdade, sendo possível elencar a biomedicina e o direito como agentes importantes para a produção de normatividades e de processos de subjetivação, que incidem diretamente sobre corpos (generificados). Os mecanismos reguladores da sexualidade, compulsoriamente heterossexual e reprodutiva, como formulado por Judith Butler e inspirados também em contribuições de obras como a de Michel Foucault, estão presentes em alguns artigos.

A dimensão dicotômica e heteronormativa, reificada através dos documentos e inscrições tecnocientíficas (como os exames clínicos para dosagem de hormônios endógenos) e das intervenções possíveis e legitimadas pela possível estabilização de terapêuticas "corretoras", está presente nos processos legais/judiciais de transição de gênero descritos por Lucas Freire, em Certificações do Sexo e Gênero: a produção de verdade nos pedidos judiciais de requalificação civil de pessoas transexuais. De acordo com a análise do autor, os pedidos de alteração do registro civil da "população LGBT" geram uma documentação que mobiliza o corpo como um registro imagético fundamental 
para a definição da legitimidade e da viabilidade do processo de transição de gênero.

Os documentos produzidos nos processos analisados por Freire "falam" (e certificam) verdades sobre sexo e gênero. 0 autor analisa como as fotografias que constam nos processos contribuem para a produção de indivíduos sexuados e generificados. Ao tratar de processos de transição de gênero, essa documentação reforça a ideia de uma inadequação do corpo ao sexo verdadeiro (psíquico, e performatizado através dos atos que constroem, visualmente, o gênero pretendido). Há, portanto, a necessidade de se defender uma incomensurabilidade entre corpo e identidade, e para este processo contribuem não apenas a autoridade do discurso científico sobre o sexo (especialistas médicos e psicólogos mobilizados em laudos), como também os registros visuais produzidos a partir das imagens dos corpos (e) das pessoas que solicitam os processos de transição.

Freire demonstra como esse processo depende da construção de uma coerência biográfica em termos de gênero. A documentação levantada nos processos, e fundamentada em imagens, opera como um mecanismo de inscrição da legitimidade dessa "incoerência" e da necessidade de sua adequação/correção/estabilização. Processo que, contudo, não está desatrelado da lógica do binarismo e das oposições tradicionais homem $\mathrm{x}$ mulher, masculino $\mathrm{x}$ feminino, e da necessidade de minimização de possíveis ambiguidades. Assim, os indivíduos que se produzem nesta documentação, mesmo em sua multiplicidade de registros imagéticos possíveis, são necessariamente sexuados e generificados. 0 binarismo sexual, e os elementos que indicam características masculinas/femininas em suas formas mais caricaturadas possíveis são mobilizados de maneiras diversas, que oscilam e variam, como 0 artigo interessantemente propõe, entre "sexo" (corpo/biologia/medicina, via laudo do Instituto Médico Legal) e "gênero" (corpo/imagem/performance, via parecer das funcionárias no NUDIVERSIS). Mas todos esses registros operam, ainda, dentro de uma linguagem normativa no que diz respeito a gênero e sexualidade.

Como argumenta Butler (2006), o diagnóstico de disforia de gênero se torna condição para 0 acesso a recursos médicos e técnicos para a redesignação de sexo, retirando a possibilidade de autodeterminação dos sujeitos, obrigados a se submeterem à linguagem da correção e adaptação às categorias de gênero, que cerceiam/congelam processos de devir. 0 diagnóstico exige a demonstração de sofrimento diante de uma inadequação ou inadaptação às categorias imaginadas 
como fixas e imutáveis. 0 problema, localizado no sujeito, resguarda a norma preservada pelos dispositivos médicos e jurídicos.

A masculinidade e feminilidade de corpos e pessoas, como elementos distintos e excludentes, ou a lógica binária do sexo como se fosse algo dado, estanque, relativamente imutável e desambiguado está também presente na forma como gênero se caracteriza como um elemento identitário e fundamental desde antes do nascimento dos bebês (CHAZAN, 2007; MACHADO, 2005).

Ao discutir 0 acesso às técnicas contemporâneas de reprodução medicamente assistida, Luciane Moás e Eliane Vargas ressaltam, em Gênero, conjugalidades e reprodução medicamente assistida: aspectos regulatórios $e$ práticas em diferentes cenários, as convenções de gênero/sexualidade/família presentes nos pressupostos sobre a reprodução, e que levam inclusive às restrições para se ter acesso a essas tecnologias. Neste sentido, discutem tanto os aspectos normativos presentes nesses pressupostos, como também a maneira como a compreensão das diversas técnicas reprodutivas em questão reflete a oposição entre "natural" (a gravidez espontânea) e "artificial" (a reprodução medicamente assistida). A tecnociência aparece, portanto, no material trazido por este trabalho, como uma forma de realizar o desejo por filhos "biológicos", mas por via do artifício, que pode ser entendida como algo não "natural". 0 acesso a esses procedimentos, como demonstram as autoras, é escalonado de acordo com outros marcadores da diferença (como classe e orientação sexual, por exemplo).

Assim como no caso dos processos de transição de gênero narrados por Lucas Freire, a discussão sobre reprodução medicamente assistida evidencia como operam os acessos a direitos ligados a gênero e sexualidade, e como biomedicina e direito atuam na produção de discursos de verdade, processos de subjetivação e de intervenção sobre os corpos em questão. Este mesmo aspecto está presente na discussão sobre intersexualidade.

Neste dossiê, ela se atualiza com 0 artigo sobre a polêmica que cerca a inclusão do teste do pezinho na lista de doenças diagnosticadas no programa de triagem neonatal. Em Rastreando corpos, produzindo sexos: a inserção da hiperplasia adrenal congênita no teste do pezinho, Janaína Freitas e Paula Sandrine Machado descrevem as controvérsias que envolvem esse processo. 0 material apresentado permite pensar que, menos que a morbimortalidade que envolveria a Hiperplasia Adrenal Congênita (uma das principais causas da intersexualidade), o que está em jogo, de fato, é a permanência da dificuldade da nossa sociedade em lidar com a ambiguidade sexual e o nascimento de bebês cuja atribuição do sexo biológico se faz menos óbvia. Deste modo, com a inclusão do 
referido teste entre os exames feitos rotineiramente em recém-nascidos, a tecnociência biomédica contribui para legitimar e para viabilizar efetivamente uma política pública que tem pressupostos e implicações, no que diz respeito a gênero, bastante claros. Os pressupostos em questão estão pautados por esta mesma heteronormatividade e pelo pensamento dicotômico que opera com a oposição de dois termos excludentes e irredutíveis: "menino" ou "menina".

Nestes artigos, portanto, biomedicina e direito agem como instâncias que reificam verdades sobre sexo e gênero, e que produzem os corpos que as podem performar/agir. E o fazem, necessariamente, a partir de uma lógica binária que opõe corpos masculinos e femininos, partindo do pressuposto de que esta é uma diferença necessária e relativamente definitiva. Assim, o binarismo de gênero continua operando como o parâmetro normativo para a existência e a agência das pessoas, como o principal organizador das subjetividades, identidades e dos próprios corpos em questão. Bebês ou adultos que transitam entre os polos desta oposição tendem, assim, a ser empurrados para um desses dois modelos de corporalidade, subjetividade e ação. As situações possíveis entre um e outro modelo são deslegitimadas ao serem consideradas como ambiguidades e indefinições que "reclamam" uma "correção" ou intervenção.

Essa dimensão normativa, para a qual contribui substancialmente a tecnociência, explicita a sua potência biopolítica. Em outras palavras, a tecnociência contribui para reificar determinados modelos de pessoas, que envolvem não somente expectativas específicas relacionadas à corporalidade, sexualidade e reprodução, mas também aspectos mais gerais da existência humana.

Rabinow e Rose (2006, p. 37) observam na atual configuração do biopoder novos circuitos de bioeconomia, novas formas de capitalização da biociência e relações de troca, nas quais empreendimentos biotecnológicos encontram novos nichos de mercado na articulação entre vida, verdade e valor, sendo necessárias análises críticas da relação entre biopolítica, biocapital e bioeconomia (p. 48). 0 autoconhecimento genético tornou-se um mercado do futuro, no sentido não só de predizer doenças ou riscos potenciais à saúde, mas também de proporcionar uma identidade ou "verdade de si".

Assumindo o desafio de mapear interconexões entre as linhas dispersas, virtuais e contingentes da biopolítica, Bruno Saliba de Paula e Yurij Castelfranchi, em Conbecer os riscos, administrar a vida: aconselhamento genético entre a biopolitica e a sociedade de controle, propõem analisar o aconselhamento genético que, ao ser contrastado com as medidas eugênicas do século passado, 
torna evidentes as modulações feitas pelo Estado, os especialistas e o mercado nesse sentido.

A possibilidade de selecionar gametas e embriões explicita determinados ideais de vida e pessoa. Havendo essa oportunidade, a seleção genética envolve a escolha por corpos com menor tendência a doenças e deficiências, e a preferência por uma prole saudável, competitiva, e "melhorada". Fundamentando este modelo, está a ideia de uma "gestão da vida" que pressupõe, como mostra 0 artigo, a visão do corpo como um equipamento dado, uma espécie de "capital humano inato", cujo monitoramento constante e permanente pela tecnociência é valorizado. As possibilidades de controle e investimento desse "capital" são dadas pelo mercado de aconselhamento genético, que se constitui paralelamente ao desenvolvimento científico e tecnológico na área da genética.

A lógica operatória da biopolítica modula as relações entre sujeitos, ciência e políticas públicas. Ao conhecerem os riscos para administrar a vida, segundo argumentam Paula e Castelfranchi, os indivíduos são chamados a ser tornarem parceiros do Estado para tomarem decisões, por exemplo, sobre prováveis riscos e terapêuticas potenciais. Todavia, é necessário lembrar, como o faz Cláudia Fonseca (2014), que embora os discursos biopolíticos penetrem os "microespaços do tecido social", eles assumem formas diversas, segundo a rede sociotécnica na qual operam.

As diversas e potentes associações entre a tecnociência e os diversos mercados "bio" se reforçam nos artigos até aqui descritos, através de exames/testes ligados à sexuação de pessoas humanas (para processos de transição de gênero ou intervenções ligadas à intersexualidade) e o mercado de aconselhamento genético. Mas há, também, todo o profícuo universo ligado mais diretamente à sexualidade e reprodução, no qual também, como veremos, incidem os mesmos padrões de normatização.

Como afirma Butler (2006, p. 128), "No se presume ninguna disfunção mental en las mujeres que toman estrógenos 0 en los hombres que toman Viagra." As ciências psi, como parte dos processos médico-legais que arbitram a redesignação sexual, têm um papel definidor nesse processo ao diagnosticar a inadequação às normas de gênero em termos de uma patologia que orienta uma intervenção cirúrgico-hormonal, como tratou o artigo de Freire. No entanto, sua intervenção se torna "desnecessária" em situações que visam aprimorar características ou funcionamentos conforme as normas tradicionais de gênero, como indica o trabalho descrito a seguir. 
0 caso do diagnóstico de deficiência androgênica (DAEM), trazido por Lucas Tramontano e Jane Russo, no artigo intitulado $O$ diagnóstico de Deficiência Androgênica do Envelhecimento Masculino e os (des)caminhos do desejo sexual masculino, demonstra como duas especialidades médicas (a urologia e a endocrinologia) disputam a tentativa de uma possível patologização, e evidentemente a respectiva intervenção medicamentosa, sobre a sexualidade masculina. Partindo das discussões sobre (bio)medicalização das sexualidades e as biopolíticas da vida, abordadas por autores como Peter Conrad, Adele Clarke e Nikolas Rose; Tramontano e Russo retratam os descaminhos na definição dos limites que permitiriam uma possível estabilização da patologização da ausência (ou da redução) do desejo e atividade sexual masculina, que oscila entre a "deficiência androgênica" (DAEM) e a "disfunção erétil" (DE).

Os autores mostram como a operação diagnóstica se torna dúbia e atrelada a concepções e expectativas subjacentes à masculinidade e ao desejo sexual masculino, que orientam as concepções acerca do corpo masculino e seu funcionamento. Desse modo, ressaltam não apenas as concepções divergentes entre especialistas e especialidades na abordagem aos "problemas" (a possível definição de algo como uma "andropausa", em suas diversas categorizações possíveis), como também às diversas hipóteses de explicação e possibilidades de acompanhamento terapêutico ofertadas por cada uma dessas especialidades.

Apesar das divergências e embates apresentados no artigo, o cenário retratado evidencia o pressuposto de um modelo heteronormativo, para o qual 0 principal parâmetro avaliativo envolve o funcionamento anatômico do pênis, tendo em vista a sua capacidade de ereção e penetração. Neste sentido, 0 aparato tecnocientífico descrito neste artigo está mobilizado para o diagnóstico e a intervenção sobre corpos para os quais se busca restabelecer (ou amplificar) um determinado tipo de performance sexual, fundamentalmente atrelada a parâmetros (generalizados) de atividade heterossexual.

As performances de gênero ajustadas e delimitadas à heterossexualidade pressupõem também certas expectativas e modelos do "feminino", encenadas por mulheres que se dedicam ao comercio de strip-tease on line. No artigo Close na web: incorporando femininos desejáveis, Weslei Lopes Silva e Juliana Gonzaga Jayme, partindo do paradigma de incorporação de Csordas e do conceito de performance de Butler, propõem analisar a ressignificação do corpo e a construção de personagens eróticos desejáveis no comércio sexual na web.

os relatos levantados no artigo indicam como as personagens femininas encenadas oscilam entre estereótipos convencionais das fantasias heterossexistas 
masculinas (como a mulher fatal, a virgem, a enfermeira, a estudante). Por outro lado, mostram também como a tecnologia de informação (computadores, webcams, internet) viabiliza performatividades diversas desses corpos para 0 sexo. Essas associações comportam um trânsito variado (ainda que dentro de padrões estereotipados e heteronormativos) de temáticas, personagens, estilos de performance, nomeações e "identidades" assumidas pelas performers, numa espécie de "nomadismo sexual" dos corpos, cuja visibilidade se torna consumível, pela rede. Provocam, também, em comparação à prostituição, um grau distinto de envolvimento das mulheres com essa atividade remunerada, que se torna possível pela utilização do ciberespaço como o lugar de encontro, onde se estabelece a relação. 0 consumo da performance do sexo via tecnologia amplifica, assim, as possibilidades de expressão das sexualidades em cena.

Contudo, o strip-tease online aciona estereótipos convencionais, que envolvem a objetificação do corpo feminino, bem como a oposição entre mulheres "para casar" (mães) e mulheres "para usar" (prostitutas, vadias). Os preconceitos ligados a esta oposição vêm sendo, inclusive, mobilizados politicamente por movimentos sociais contemporâneos e suas bandeiras (por exemplo, com a "Marcha das Vadias", cf. SORJ e GOMES, 2014). A atualidade dessa discussão sugere a persistência de uma crítica a valores relacionados ao "patriarcado", apesar de todo o desenvolvimento da teoria feminista e dos estudos de gênero nas últimas décadas, que têm trabalhado na desconstrução das teorias essencialistas, na complexificação do entendimento das relações de gênero, e na libertação das múltiplas possibilidades de expressão das sexualidades, inclusive da heterossexualidade feminina e da comercialização do sexo.

Há, nesse sentido ligado aos estereótipos de gênero, um contraponto possível com o material empírico apresentado por Fernanda Vecchi Alzuguir e Marina Nucci, em Maternidade mamífera: concepções sobre natureza e ciência em uma rede social de mães. No artigo, as autoras mostram como a maternidade biológica e a natureza feminina têm aparecido em redes sociais de mães. Ao reivindicar o estatuto de "mamíferas" e o direito à amamentação prolongada e ao parto natural, em reação às protocolares (e frequentemente violentas) intervenções obstétricas, as temáticas trazidas no artigo a partir de blogs e grupos de discussão reafirmam o corpo feminino como eminentemente reprodutivo, e a ligação com a natureza e a animalidade se atualiza na valorização de uma vivência plena da maternidade biológica, altamente corporificada.

As redes sociais digitais surgem, assim, como uma via privilegiada para condensar informações acerca das técnicas corporais que envolvem o parto e a 
amamentação, bem como estratégias políticas de resistência à medicalização de ambos, e do próprio puerpério e infância dos bebês. Como indicam, a partir de contextos empíricos distintos, outros trabalhos (TORNQUIST, 2002; FLEISCHER, 2011; CARNEIR0, 2014), a "natureza" é diretamente mobilizada como algo a ser resgatado e reaprendido, de forma a compensar um processo prévio de desaprendizagem, resultante da estabilização da tecnociência voltada à reprodução nos últimos séculos.

Recorrendo a Londa Schibienger, as autoras ressaltam um paradoxo entre a resistência a esse processo de alienação em relação ao próprio corpo - ao buscarem gestar, parir e amamentar "naturalmente" - e a sustentação desse discurso numa categoria também científica: a de mamíferas. Esse paradoxo comporta também, como destacam as autoras, a radicalização de um essencialismo, cujos aspectos excludentes e pouco libertários foram criticados por vários dos movimentos feministas a partir da segunda metade do século XX. 0 modelo de feminilidade enfatizado nesse material estudado, a de uma mãe dedicada integralmente aos cuidados maternos, está também restrito a um perfil bastante limitado em termos de classe social e configurações familiares/afetivas. 0 corpo, novamente, em sua materialidade, tem um lugar fundamental nesse cenário: não somente a maternidade biológica é valorizada, como também a visceralidade das experiências de gestar, parir e amamentar.

Persiste, como podemos ver a partir deste artigo, a oposição entre natureza e cultura: o corpo feminino e os processos fisiológicos em questão são vistos como eminentemente "naturais" e essas experiências viscerais são vistas como processos que precisam ser reapropriados politicamente pelas mulheres/mães. Considerando a história da relação entre mulheres e (tecno)ciência, e a centralidade dos aspectos reprodutivos subjacente a ela, as críticas (re)colocadas por esses movimentos enfatizam as dimensões autoritárias e misóginas das tecnociências biomédicas. 0 protagonismo reivindicado pelas mulheres contribui, em certa medida, para o reforço de uma seletiva visão tecnofóbica, direcionada ao aparato e aos procedimentos médicos, sobretudo obstétricos.

Como também indicam as pesquisas supracitadas sobre essa temática, a reapropriação das mulheres sobre seus próprios processos corporais (bandeira persistente na agenda política desde o feminismo de segunda onda) tem implicado o questionamento de determinados procedimentos técnicos e, muitas vezes, a recusa completa do modelo normativo dos serviços (públicos e privados) de obstetrícia e pediatria (sobretudo no apoio ao puerpério e à amamentação). Tal processo é concomitante ao fortalecimento das redes de mulheres/mães 
(frequentemente digitais, mas não apenas) e à circulação de informações sobre essas técnicas corporais alternativas e suas respectivas estratégias de resistência.

Essa forma de ativismo político, que envolve de certa maneira a disputa pela expertise sobre o corpo reprodutivo pela via da experiência corporificada, tem produzido impactos significativos sobre os serviços de saúde ligados ao parto e à reprodução. ${ }^{14}$ Neste contexto, as disputas e embates se situam, fundamentalmente, sobre as técnicas corporais (MAUSS, 2003) que envolvem a reprodução. No que se refere aos processos de parto e amamentação, como vimos, a própria necessidade da mediação tecnocientífica é colocada em questão, em detrimento de outras formas de aprendizado corporal, descoladas dos seus aparatos e protocolos, e numa via anti-biomedicalização que enfatiza a autonomia das mulheres sobre esses processos.

Ainda que em Mauss as técnicas corporais aparecessem como processo biopsicossocial (ou seja, um processo complexo que envolveria todas essas dimensões presentes nas experiências humanas), podemos observar que, nestas estratégias feministas contemporâneas, as "técnicas" disponibilizadas pela tecnociência e pela biomedicina eventualmente são vistas como algo que, com mais segurança do que fomos levadas a acreditar, pode ser em parte ou até integralmente recusado. Ou no mínimo, apesar de toda a ambiguidade presente na expressão, precisaria ser "humanizado" (TORNQUIST, 2002; CARNEIRO, 2014).

Nesses processos, corpo, natureza e tecnociência são elementos contrastantes de diversas posições (individuais, institucionais, coletivas), que se matizam entre uma tecnofobia radical (o caso de mulheres que voltaram a parir em casa, por exemplo) e uma tecnofilia total (cesáreas agendadas previamente para conforto de médicos e familiares, por outro lado). Técnicas e tecnologia, e seus diversos agenciamentos em corpos (sexuados/generificados), permanecem questões fundamentais.

Em Tecno-redención de cuerpos transexuales: Apropiación tecnológica y autogestión de identidades inconclusas, Alejandra Roca e María Alejandra

\footnotetext{
${ }^{14}$ Para citar um exemplo, as redes de maternidade ativa e as discussões sobre "violência obstétrica" e a "epidemia de cesarianas" no Brasil participaram do processo político que culminou na aprovação da Resolução Normativa 368, em 06 de janeiro de 2015. A resolução regulamenta 0 fornecimento de informações sobre taxas de parto normal e cesarianas pelas operadoras de saúde, e fornece parâmetros para alguns procedimentos obstétricos, visando uma maior autonomia das mulheres sobre o processo. Sobre isso, ver também os resultados da pesquisa "Nascer no Brasil", publicados nos Cadernos de Saúde Pública, vol.30 supl.1, 2014.
} 
Dellacasa trazem essa discussão sobre corpo, sexualidade e natureza através de uma análise dos processos médico-legais de redesignação do sexo em pessoas transexuais na Argentina. No caso de sujeitos que desejam fazer a transição de gênero, 0 acesso às tecnologias que possibilitam esse processo ganha dimensões "redentoras", resolvendo a angústia e a sensação de "inadequação" que relatam pessoas trans em relação aos seus corpos "originais".

Não se trata, nesse caso, de performar o gênero através de aparatos inteligiveis como gestos, roupas, sapatos, maquiagem, por exemplo, mas de se apropriar de recursos biotecnológicos como os diversos hormônios sexuais disponíveis no mercado, silicones e próteses diversas, e de diversos tipos de procedimentos cirúrgicos, para operar no corpo as transformações necessárias, que podem (ou não) visar a estabilização de um determinado "sexo/gênero".

No artigo de Roca e Dellacasa, para as pessoas que buscam a transição de gênero através das cirurgias e procedimentos de redesignação sexual, o corpo aparece como um "projeto" e o acesso às transformações desejadas, que depende da apropriação desses recursos, sugere a sua positividade. Contudo, como também mostra 0 trabalho de Freire, neste volume, o acesso a esses recursos pressupõe uma coerência entre o corpo e a identidade de gênero e, portanto, um processo de "normalização" dos corpos e de direcionamento dos recursos tecnológicos no sentido de estabelecer essa coerência.

Como argumentam as autoras, essa positivação pode ganhar aspectos salvacionistas ou "soteriológicos", e o acesso aos recursos é visto, numa proposta transhumanista, como um direito à transformação, à mutação do próprio corpo, numa atualização da proposta de pensar os desejos que tornam possíveis realidades corporais como a fusão corpo/máquina, presente na figuração ciborgue. Roca e Dellacasa contrapõem essa perspectiva a um "bioconservadorismo", que recusaria qualquer aliança com esses dispositivos. Algo próximo talvez do universo empírico descrito no artigo sobre as mães "mamíferas".

\section{ARTEFATOS TECNOCIENTÍFICOS E AGENCIAMENTOS POSSÍVEIS}

Um exemplo de radicalização dessa proposta tecnofílica é o trabalho de Beatriz/Paul Preciado (2008) que, em "Testo Yonqui" relata e reflete sobre sua experiência pessoal com 0 uso da testosterona. Preciado propõe uma tecnopolítica de gênero alinhada à proposta queer de recusa às normatividades (de gênero e de sexualidade), ampliando as possibilidades de expressão pessoal/corporal sem uma 
formatação previamente dada e sem a obrigação de submissão a modelos preexistentes. É uma proposta subversiva, ainda que, ou por isso mesmo, controversa (RADI, 2015), tendo em vista a persistência contemporânea de valores e práticas sociais misóginas, homo/bi/transfóbicas; e dos binarismos homem/mulher, masculino/feminino. Ou, como concebe Cabral (2005), da persistência prescritiva da diferença sexual como valor ou da bioanatomia como mandato.

Estas oposições e "identidades" ainda estruturam nosso pensamento e limitam nossas possibilidades sociais de existência, apesar de toda a tinta (e todo 0 sangue) que já se gastou construindo a crítica a elas, e das ainda tímidas conquistas no plano médico e jurídico para aceder possibilidades de autodeterminação. ${ }^{15}$ A proposta é subversiva também no sentido em que recusa radicalmente a tecnofobia, e explora a "margem de indeterminação" (SIMONDON, 1969) dos procedimentos e objetos tecnocientíficos, como os hormônios sexuais. Preciado (2008) explicita, e valoriza politicamente, a complexidade inerente à possibilidade de um uso desviante, ou mesmo junkie, dessas substâncias, que caracteriza como "drogas políticas", criadas e formatadas inicialmente para outro propósito:

las hormonas son ficciones biopolíticas, ficciones que pueden tomarse, digerirse, incorporarse, artefactos biopolíticos que crean formaciones corporales y se integran a los organismos políticos mayores, tales como las instituciones político-legales y el estado-nación (PRECIADO, 2007, $\mathrm{s} / \mathrm{p})$.

Como narra Preciado (2008), os hormônios sexuais geram efeitos reais, tanto nos corpos (processos de modificação celular e crescimento de pelos, mudança de voz, das formas e texturas do corpo) como no "gênero" (referindo-se ao seu próprio processo de masculinização, que lhe teria permitido, por exemplo, experimentar privilégios reservados aos homens).

Ancorada/o numa experiência histórica de pouca autonomia perante os recursos produzidos por toda a maquinaria que envolve capitalismo e tecnociência; e em consonância com a provocação trazida por Haraway (2000) através da figura do ciborgue, Preciado (2008) propõe explorar, no próprio corpo, essa potência política dos artefatos sociotécnicos da biomedicina voltada para

\footnotetext{
${ }^{15}$ Para uma discussão sobre autonomia e eleição condicionada no contexto do acesso aos recursos médicos e técnicos para a redesignação sexual, ver Butler (2006).
} 
gênero e sexualidade, que caracteriza como partes de um regime "farmacopornográfico". Assim, experimenta as possibilidades "excedentes" aos propósitos regulamentados e regulamentares dos hormônios sexuais, e argumenta que esse uso desviante deve contribuir para contestar as normatividades que regulam a nossa existência, bem como as possibilidades de existência e circulação dessas substâncias no mundo.

A "vida social dos medicamentos" (VAN DER GEEST et. al., 1996) ${ }^{16}$ implica um processo de socialização no qual estão engajados, em associações curiosas, perversas e algumas vezes criativas, cientistas e empresários, usuários (e) ativistas, mercados, governos e agências internacionais. A bula dos remédios retrata, como uma fotografia, um momento dessas associações: o que entra como indicação e posologia, ou o que é considerado "efeito colateral", pode variar. A pílula anticoncepcional, antes de ter seu uso devidamente regulamentado e autorizado figurava como um "regulador de ciclos menstruais"; o misoprostol (Cytotec), originalmente um medicamento para a úlcera gástrica, tem uso bastante popularizado como medicamento abortivo; 0 sildenafil (Viagra), atualmente usado para disfunção erétil, foi inicialmente testado como um medicamento para o coração. 0 que define, portanto, o destino de um princípio ativo em um corpo é uma multiplicidade de engajamentos e possibilidades, que envolve a sua agência (os efeitos corporais que a substância é capaz de produzir), bem como a tecnociência e a biomedicina, e as instâncias reguladoras do mercado e das instituições governamentais.

Podemos ler o Manifesto Ciborgue (HARAWAY, 2000) como uma das primeiras reações à tecnofobia ou ao bioconservadorismo. E de fato, com sua perspicácia política, Haraway nos conduz por um caminho menos simplificador do que supõe aquele que vê a ação humana (principalmente aquela que costumamos criticar, tecnocientífica, biopolítica) como algo de que podemos, simplesmente, abrir mão. Não se trata, contudo, como ela enfatiza em vários momentos, de uma tecnofilia acrítica. E sim de uma perspectiva que explora e considera uma possibilidade política nessa aliança, tendo em vista sua relativa inevitabilidade (ou nossa incapacidade/inabilidade política para torná-la inevitável, quando e se desejado).

Boa parte do material empírico e analítico que os estudos de gênero e os estudos sociais das ciências têm trazido indica a persistência da oposição entre natureza e cultura como categorias de entendimento do mundo e da nossa ação

\footnotetext{
${ }^{16}$ Sobre isso, ver também o dossiê sobre Antropologia e Medicamentos: Revista R@u, UFSCar, v.4, n.1. 2012.
} 
sobre ele e, nessa linha, a permanência, reconfigurada, da ideia de que a (bio)tecnologia e a tecnociência "subvertem a natureza". ${ }^{17}$ Isto sugere um descompasso em relação às críticas produzidas pelo universo de pesquisas aqui explicitado. E atualiza a tradição de reflexão socioantropológica, dedicada a pensar a complexidade da questão da presença e ação humana no mundo, seus engajamentos diversos, e a magnitude dos seus efeitos.

Neste sentido, há ainda um caminho a ser trilhado para dar visibilidade à diversidade de elementos presentes nas relações entre tecnociências, corpos, gênero e sexualidade. Sobretudo, nos processos que envolvem as técnicas corporais e o lugar das tecnociências em suas dinâmicas, uma vez que os artefatos tecnocientíficos disponíveis podem, na sua própria agência e margem de indeterminação, tanto funcionar a favor da "biopolítica", do "capitalismo" ou da "sociedade de controle", como operar como recursos libertários ou contestadores das normas vigentes, permitindo irrupções e trânsitos, e concretizando transformações possíveis.

\section{REFERÊNCIAS}

BUTLER, Judith. Problemas do gênero: Feminismo e subversão da identidade. Rio de Janeiro: Civilização Brasileira, 2003.

BUTLER, Judith. Deshacer el género. Barcelona: Paidós, 2006.

CABRAL, Mauro I. Caballo de troya. Transmaculinidades, derechos sexuales y derechos reproductivos. Memorias del Seminário - Campaña por la convención de los derechos sexuales y los derechos reproductivos. Lima, Perú, Septiembre, 2005.

CARNEIRO, Rosamaria. G. De perto e de longe do que seria natural, mais natural e/ou humanizado: uma etnografia dos grupos de preparo para o parto humanizado. In: FLEISCHER, Soraya; FERREIRA, Jaqueline. (Org.). Etnografias em Serviços de Saúde. 1ed. Rio de Janeiro: Garamond, 2014, p. 243-266.

CHAZAN, Lilian Krakowski. "Meio quilo de gente": um estudo antropológico do ultrassom obstétrico. Rio de Janeiro: Ed. Fiocruz, 2007.

\footnotetext{
${ }^{17}$ A oposição "cis" e "trans" poderia ser pensada, por exemplo, como uma atualização da oposição entre natureza e cultura.
} 
CITELI, Maria Teresa. Mulheres na ciência. Cadernos Pagu (15), Campinas, 2000, p. $15-38$.

CORRÊA, Mariza. Fantasias corporais. In: PISCITELLI, Adriana; GREGORI, Maria Filomena; CARRARA, Sérgio. Sexualidades e saberes: convenções e fronteiras. Rio de Janeiro: Garamond, 2004.

FAUSTO-STERLING, Anne. Sexing the Body. Nova York: Basic Books, 2000.

FLEISCHER, Soraya. Parteiras, buchudas e aperreios. Uma etnografia do atendimento obstétrico não oficial em Melgaço, Pará. Belém: Paka-Tatu; Santa Cruz do Sul: EDUNISC, 2011.

FONSECA, Claudia. Parentesco, tecnologia e lei na era do DNA. Rio de Janeiro: EdUERJ, 2014.

FOUCAULT, Michel. História da sexualidade. Vol.1. A vontade de saber. Rio de Janeiro: Edições Graal, 1988.

FOUCAULT, Michel. Aula de 17 de março de 1976. In: FOUCAULT, Michel. En defesa da sociedade. Curso no Collège de France (1975-1976), São Paulo: Martins Fontes, 2005.

GROSZ, Elisabeth. Corpos reconfigurados. Cadernos Pagu (14), Campinas, 2000, p. 45-86.

HARAWAY, Donna. Primate visions: gender, race and nature in the world of modern science. New York, London: Routledge, 1989.

HARAWAY, Donna. Saberes localizados: a questão da ciência para o feminismo e 0 privilégio da perspectiva parcial In: Cadernos Pagu (5), Campinas, 1995, p. 07-41. HARAWAY, Donna.

Modest_Witness@Second_Millennium.FemaleMan $@$ Meets_OncoMouse ${ }^{\mathrm{TM}}$. London: Routledge, 1997.

HARAWAY, Donna. Las promesas de los monstrous: una política regeneradora para otros inapropiados/bles. Política y Sociedad, 30, 1999a, Madrid, p. 121-163.

HARAWAY, Donna How like a leaf: an interview with Thyrza Nichols Goodeve / Donna J. Haraway. New York and London: Routeldge, 1999b.

HARAWAY, Donna. Manifesto ciborgue: ciência, tecnologia e feminismo-socialista no final do século XX. in: SILVA, Tomaz Tadeu da. Antropologia do ciborgue: as vertigens do pós-humano. Belo Horizonte: Autêntica, 2000. 
HARAWAY, Donna. "Gênero" para um dicionário marxista: a política sexual de uma palavra. Cadernos Pagu (22) 2004, Campinas. p. 201-246.

HARAWAY, Donna e GOODEVE, Thyrza Nichols. Fragmentos: quanto como uma folha. Entrevista com Donna Haraway . Mediações Vol. 20, n.1 (Jan./Jun. 2015) Londrina, 2015, p. 48-68.

KELLER, Evelyn Fox. Qual foi o impacto do feminismo na ciência? Cadernos Pagu (27), Campinas, 2006, p. 13-34.

LATOUR, Bruno. Jamais fomos modernos: ensaios de antropologia simétrica. São Paulo: Editora 34, 1995.

LATOUR, Bruno. Ciência em ação: como seguir cientistas e engenheiros sociedade afora. São Paulo: Editora Unesp, 1997.

LATOUR, Bruno. Reassembling the Social: an introduction to Actor-NetworkTheory. New York: Oxford University Press, 2005.

LOPES, Maria Margaret. Sobre convenções em torno de argumentos de autoridade. Cadernos Pagu (27), 2006, p. 35-61.

MACHADO, Paula Sandrine. 0 sexo dos anjos: um olhar sobre a anatomia e a produção do sexo (como se fosse) natural. Cadernos Pagu (24), Campinas, 2005, p. 249-281.

MARTIN, Emily. The egg and the sperm: how science has constructed a romance based on stereotypical male-female roles. Signs: Journal of Women in Culture and Society. 1991, vol. 16, no.3.

MAUSS, Marcel. As técnicas do corpo. In: MAUSS, Marcel. Sociologia e Antropologia. São Paulo: Cosac\&Naify, 2003. p. 401-422.

MOL, Annemarie. Ontological Politics: A Word and Some Questions. In: LAW, John and HASSARD, John (Eds.). Actor Network Theory and After. London: Blackwell, 1998.

MOL, Annemarie. The Body Multiple: Ontology in Medical Practice. Durham, N.C.: Duke University Press, 2002.

MOL, Annemarie. Other Words: Stories from the Social Studies of Science, Technology, and Medicine. Fieldsights - Theorizing the Contemporary. Cultural Anthropology Online, January 13, 2014.

OUDSHOORN, Nelly. Beyond the natural body: an archeology of sex hormones. London and New York: Routledge, 1994. 
PRECIADO, Beatriz. Biopolítica del género. In: AA.W. Biopolítica. Buenos Aires, Ediciones Ají de Pollo, 2007.

PRECIADO, Beatriz. Testo Yonqui. Madrid: Editora Espasa Calpe, 2008.

PUGLIESE, Gabriel. Sobre o "Caso Marie Curie": a radioatividade e a subversão do gênero. São Paulo: Alameda, 2012.

PUGLIESE, Gabriel. 0 gênero da ciência: reflexões sobre a Teoria Ator-Rede e a perspectiva feminista. Mediações Vol. 20, n.1 (Jan./Jun. 2015) - Londrina, 2015, p. 69-88.

RADI, Blas. Desfundamentos e pós-fundações. Revoluções conservadoras, tecnologias de apropriação e apagamento de corpos e subjetividades trans na obra de Preciado. Sexualidades, n.12, Julho, 2015. Disponível em:

http://www.irnweb.org/wpcontent/uploads/2015/07/Sexualidades_No.12_Jul_2015.pdf,

RABINOW, Paulo; ROSE, Nikolas. 0 conceito de biopoder hoje. Política \& Trabalho - Revista de Ciências Sociais, n.24, João Pessoa, Abril de 2006, p. 27-57.

ROHDEN, Fabíola. 0 corpo fazendo a diferença. Mana, v. 4 n.2, Rio de Janeiro, out. 1998, p. 127-141.

ROHDEN, Fabíola. A ciência da diferença: sexo e gênero na medicina da mulher. Rio de Janeiro: Fiocruz, 2001.

RUBIN, Gayle. The Traffic in Women: Notes on the Political Economy of Sex. In: REITER, Rayna Rapp. (ed.) Toward an Anthropology of Women. New York: Monthly Review, 1975.

SALIH, Sarah. Judith Butler e a Teoria Queer. Belo Horizonte: Autêntica Editora, 2012.

SCHIEBINGER, Londa. Mais mulheres na ciência: questões de conhecimento.

História, Ciências, Saúde - Manguinhos, Rio de Janeiro, v.15, suplemento, jun., 2008, p. 269-281.

SIMONDON, Gilbert. Du mode d'existence des objets techniques. Paris:

Montaigne, 1969.

SORJ, Bila; GOMES, Carla. Corpo, geração e identidade: a Marcha das Vadias no Brasil. Sociedade e Estado. Brasília, UnB, v. 29, 2014, p. 433-447. 
STRATHERN, Marilyn. No nature, no culture: the Hagen case. In: MacCORMACK, Carol and STRATHERN, Marilyn (eds). Nature, Culture and Gender. Cambridge: Cambridge University Press, 1980.

STRATHERN, Marilyn. O gênero da dádiva: problemas com mulheres e problemas com a sociedade na Melanésia. Campinas: Ed. Unicamp, 2006.

TORNQUIST, Carmen Susana. Armadilhas da nova era: natureza e maternidade no ideário da humanização do parto. Revista Estudos Feministas. v. 10, n. 2, 2002.

VAN DER GEEST, Sjaak; WHITE, Susan Reynolds; HARDON, Anita. The anthropology of pharmaceuticals: a biographical approach. In: Annual Review of Anthropology, 1996, Vol. 25, p. 153-178.

WOOLGAR, Steve e LEZAUN, Javier. The wrong bin bag: A turn to ontology in science and technology studies? Social Studies of Science, vol. 43 no. 3. June 2013, p. 321-340. 